\title{
POPULATION POLICY, FERTILITY RATES AND HEALTH SECTOR DEVELOPMENT IN NIGERIA
}

\author{
Dachi Iwara Arikpo ${ }^{1,2}$, Bassey Enya Ndem ${ }^{1}$ and Uchechi Rex Ogbuagu ${ }^{1}$ \\ ${ }^{1}$ Department of Economics, University of Calabar \\ ${ }^{2}$ Institute of Tropical Diseases Research and Prevention, University of Calabar Teaching Hospital, \\ University of Calabar
}

DOI: 10.46609/IJSSER.2020.v05i12.017 URL: https://doi.org/10.46609/IJSSER.2020.v05i12.017

\begin{abstract}
In the face of continued population growth rates in Nigeria, we examined population policies that have been enacted in Nigeria for their effectiveness in attaining stipulated population control targets. Using an evaluation methodology, we x-rayed these policies and the reasons for their perceived inability to check population growth and fertility rates. We placed emphasis on the health-related targets of the policies and examined the capacity of the health sector to deliver on these targets. We conclude that a functional and effective primary health care system for implementing population control strategies and attainment of health-related population targets.
\end{abstract}

Keywords: population, policy, fertility rates, health sector

\section{Introduction}

The health sector of any country, has been identified as crucial for attaining optimum welfare and socioeconomic advancement $(\mathrm{CMH}, 2001)$. This is because of the feedback relationship that is said to exist between health and economic development. Be that as it may, this relationship is subject to moderation by population dynamics, because a high/unchecked population growth rate has the potential of dampening economic development efforts, through its effects on poverty, food security, employment, inequalities, human capital development-health and education, access to adequate clothing and housing, and individual capabilities and functioning. The sum total of this effect is as postulated in the Malthusian 'population trap' where by continuous population growth leads to "poverty and pauperisation due to the finite nature of natural resources" (Luci and Thevenon, 2010).

In the wake of the strive to met the targets of the Sustainable Development Goals (SDGs), there have been calls for adequate population control measures especially those that check fertility rates to be put in place in other to maximize the gains of diverse economic development 
International Journal of Social Science and Economic Research

ISSN: 2455-8834

Volume:05, Issue:12 "December 2020"

measures. Specifically, Principle 8 of the Rio Declaration, (UN, 1992) and Principle 6, Chapter 11 of the ICPD Programme of Action, (UN, 1994) both call for the elimination of unsustainable patterns of production and consumption; and the promotion of appropriate demographic (population related) policies in order to achieve sustainable development. These declarations placed the need for population control on the spotlight even before the launch of the SGDs in 2015.

Be that as it may, the effectiveness of population control measures without an efficient and functioning health system has been called to question. Population control measures that seek to lower fertility and slow down population growth via access to family planning, access to sexual and reproductive health care, reduction of teenage pregnancies, lowering of infant, child and maternal mortality, amongst others, require an effective health sector for the successful implementation of these policies and delivery of these services. It is worthy of note, the emphasis by the United Nations for state to pursue population policies that address population dynamics by enlarging, rather than restricting, individual choices and opportunities, essentially humancentered and rights-based approaches (UNFPA, 2012).

Nigeria is the most populous country in Africa with a population of approximately 202million people in 2018, and accounts for about half of West Africa's population (World Bank, 2019). The country is currently the 7thmost populous country worldwide and by 2050 projection, the country will be the 4th most populous country globally (United Nations, 2017). In addition, Nigeria is one of the fastest growing sub-Saharan African countries with a total fertility rate (TFR) of 5.3 births per woman in 2018, which is reported to have declined from 6.0 in 1990(NDHS, 2018). Nigeria has a high fertility rate compared to Latin America and Asia with TFR of 2.6, and North Africa and Western Asia with TFRs of 3.5 births per woman. High fertility is defined as a total fertility rate (TFR) of 5.0 or higher, and the TFR represents the average lifetime births per woman implied by the age-specific fertility rates prevailing in one historical period (World Bank, 2010). Fertility transition has been especially slow in Nigeria with fertility declined of 1.5 only in about 35 years, from 6.8 (in the 1980s) to 5.3(in 2018) children per woman (NDHS, 2018). The current rates of fertility in the country, coupled with future projections of high fertility in Nigeria, paints a grim picture and may be detrimental to Nigeria's socio-economic advancement and attaining the SDGS, given the consequences of high fertility rates on child health and schooling, maternal health, economic growth, demographics dividend and the natural environment (World Bank, 2010). As shown by the statistics presented above, high population rates have persisted in Nigeria since the 1980s. This has warranted the need for a robust population policy to check high fertility rates and population growth rates. In response to this, there have been population policies which were enacted in 1988 and 2004 respectively. These policies are believed to have been ineffective (Adegbola, 2008;Shofoyeke, 


\section{International Journal of Social Science and Economic Research}

ISSN: $2455-8834$

Volume:05, Issue:12 "December 2020"

2014; Alaba, 2017) due to sundry reasons, including the health sectors preparedness to meet up with delivering interventions especially those targeted at lowering fertility levels. It is on this premise that this paper examines population policies in Nigeria along with the health sector development overtime in keeping with the demands of these policies. We employ an evaluation methodology in describing the trends and developments in the implementation of the population policy and the health sector in Nigeria.

\section{Theoretical Framework and Literature review of population policies in Nigeria}

The need for population checks or controls is anchored on the Malthusian theory of population growth. Rev. Malthus' theory can be summarized as, "there cannot be increase in population without the means of subsistence; population invariably increases with available means of subsistence; and that population cannot be checked without producing misery or vice".

In Nigeria, the first Population Policy aimed at reducing population growth was enacted in February 1988. It was written in collaboration between the Federal Ministry of Health and the World Bank (Adegbola, 2008). The policy aimed at providing a framework and guidelines for resolving the looming population crisis employing a logical and pragmatic approach, given that the Buhari's regime (1983-85) and the Babangida's regime (1985-93), identified that Nigeria's sustained population growth was accompanied by unfavorable consequences on the welfare of citizens and the socioeconomic development of the country (Obono, 2003). Therefore, the need for a population policy to foster development, progress and self-reliance. The goals of the 1988 policy included: improving the standard of living and quality of life, promoting health and welfare, reducing population growth rate, achieving balanced rural-urban development.

The targets of the policy were stipulated as 'for the protection of the health of mother and child',

- To reduce the proportion of women who get married before the age of 18 years by 50 per cent by 1995 and by 80 per cent by the year 2000;

- To reduce the proportion of women bearing more than four children by 50 per cent by 1995 and by 80 per cent by the year 2000 ;

- To extend the coverage of family planning service to 50 per cent of women of childbearing age by 1995 and 80 per cent by year 2000;

- To reduce the number of children a woman is likely to have during her lifetime, now over 6 , to 4 per woman by year 2000

- reduce the present rate of population growth from about 3.3 per cent per year to 2.5 per cent by 1995 and 2.0 per cent by the year 2000 


\section{International Journal of Social Science and Economic Research}

ISSN: $2455-8834$

Volume:05, Issue:12 "December 2020"

(Federal Republic of v Nigeria 1988: 13-14).

In terms of reducing the population growth rate, the policy sought to,

- Promote awareness of population growth and its effects on development

- Educate young people on population matters prior to the ages of marriage and childbearing

- Provide family planning services

- Manage the needs of in fecund and sub-fecund couples

- Regular collection of demographic data and the use of such data for economic and social development planning.

The overarching target of the 1988 population policy, was to reduce the number of children a couple would have from 6 above to 4 by 1995 mainly through family planning. This policy was however unsuccessful especially in the Northern part of the country (Adegbola 2008; Mundi \&Dakyes, 2016) and many reasons have been put forward to account for the failure of this policy.

Obono (2003) opines "that the failure of the policy was due to its large and ambitious aims, coupled with the disregard of male reproductive motivation". Adegbola (2008) assessed the policy as unsuccessful due to cultural, religious and financial factors in play, including flaws in the implementation strategy adopted for the National Population Program as well as due to a cultural aversion to family planning in Northern Nigeria. Other factors that are believed to have contributed to the failure of the policy, include traditional support for high fertility in Africa(Casterline 2001), differences in religion(Mazrui1994), and suspicious among various ethnic groups (Renne 1996, Avong 2000).

With the emerging population issues and challenges as highlighted by the 1991 National Population Census, the 1994 International Conference on Population and Development, the underperformance of the 1988 population policy, the 1999 HIV/AIDs summit in Abuja, and the targets millennium development goals (MDGs) by 2015, there was the need for a revised policy that took these emerging issues into account. Subsequently, the population policy was revised in 2004. The revised policy was named the "National Policy on Population for Sustainable Development". It was launched in 2005, and had year 2015 as the end date of the targets. Worthy of note, is the fact that these emerging issues were pointers to the nexus between population dynamics and health. This is evident in the proportion of healthrelated targets as contained in the policy, as seven of them required the health system for 


\section{International Journal of Social Science and Economic Research}

ISSN: $2455-8834$

Volume:05, Issue:12 "December 2020"

implementation/ service delivery as they bordered on family planning, mortality rates and HIV morbidity.

The key targets of the 2004 policy were to

- achieve a reduction of the national population growth rate to $2 \%$ or lower by the year 2015

- achieve a reduction in the total fertility rate(TFR) of atleast 0.6 children every five years

- increase the modern contraceptive prevalence rate by at least $2 \%$ point per year

- $\quad$ reduce infant mortality rate to 35 per 1,000 live births by 2015

- $\quad$ reduce child mortality rate to 45 per 1,000 live births by 2015

- reduce maternal mortality to 125 per 100,000 live births by 2010 and 75 by 2015

- achieve a 25 percent reduction in HIV adult prevalence every five years

- Eliminate gap between men and women in enrolment in secondary, tertiary, vocational, and technical education and training by 2015

- Eliminate illiteracy by 2020

- Achieve sustainable universal basic education as soon as possible prior to the year 2015

(Federal Republic of Nigeria, 2004)

According to Mundi \&Dakyes (2016), the revised policy was to achieve among others, a balance between the rate of population growth, available resources and socio-economic development of the country, progress towards a complete demographic transition to reasonable birth rates and low death rates; improvements in the reproductive rates and low death rates; acceleration of a strong and immediate response to HIV/AIDS epidemic and other related infectious diseases; and progress in achieving balanced and integrated urban and rural development.

Despite these policies, Nigeria's population has continued to grow rapidly over this time, and was estimated as 188.9 million in2015, which represents an increase of more than 46 million people since the first National Population Policy was formulated. In addition, Nigeria's population growth rate has remained high (estimated 3.2 percent per annum) and failed to meet the policy's first target (NPopC, 2009). Tables 1 and 2 show the total fertility rates from 1990 to 2014, and the TFRs by regions in 2003 and 2008. 
International Journal of Social Science and Economic Research

ISSN: 2455-8834

Volume:05, Issue:12 "December 2020"

Table 1: Total Fertility Rate of Nigeria between 1980 and 2014

\begin{tabular}{|l|l|l|}
\hline Year & Target & Total fertility rate (TFR) \\
\hline $1980-85$ & & 6.9 \\
\hline $1985-90$ & & 6.7 \\
\hline $1990-95$ & 4 & 6.4 \\
\hline $1995-2000$ & & 5.9 \\
\hline 2003 & & 5.7 \\
\hline 2008 & $\begin{array}{l}4.3 \text { by } 2015, \text { at a } 0.6 \text { reduction rate every } \\
5 \text { years }\end{array}$ & 5.5 \\
\hline $2013 / 2014$ & & 5.7 \\
\hline 2018 & & 5.3 \\
\hline
\end{tabular}

Source: UN population division, NPC\&ORC Macro 2014, NDHS 2018

Table 2: Total Fertility Rate of Nigeria by Regions between 2003 and 2018

Region

North-East

North-west

North-central

South-East

South-west

South-south

Urban

Rural

Total
2003

7.0

6.7

5.7

4.1

4.1

4.6

4.9

6.1

5.7
2008

7.2

7.3

5.4

4.8

4.5

4.7

4.7

6.3

5.7
2018

6.1

6.6

5.0

4.7

3.9

4.0

4.5

5.9

5.3

Source: NPC 2004, NPC \&ORC Macro 2009, NDHS 2018 
A review of the implementation of 2004 population policy by a joint assessment team composed of the National Population Commission (NPC), and the Health Policy Project (HPP) was undertaken in 2015. This review was warranted by the sustained rapid population growth, high maternal and infant mortality, amongst other poorly performing areas of the policy. The report showed that although the 2004 population policy "addressed the prevailing development issues of the time, it was not effectively implemented at national, state, and local government levels" (NPC, 2015). Their report highlighted the following gaps:

Table 3: Gaps in meeting the targets of the 2004 National Population Policy

\begin{tabular}{|l|l|l|l|}
\hline Target & $\mathbf{2 0 1 5}$ goal & $\mathbf{2 0 1 3} / \mathbf{2 0 1 4}$ & Gap \\
\hline $\begin{array}{l}\text { Reduce national population growth rate to 2 percent } \\
\text { or lower by 2015 a }\end{array}$ & $\leq 2 \%$ & $3.2 \%$ & $\mathbf{1 . 2}$ percentage points \\
\hline TFR declines by at least 0.6 children every 5 years & 4.38 & 5.5 & 1.12 children \\
\hline $\begin{array}{l}\text { Increase mCPR by at least 2 percentage points per } \\
\text { year }\end{array}$ & 30.2 & 9.8 & 20.4 percentage points \\
\hline $\begin{array}{l}\text { Reduce the infant mortality rate to } 35 \text { per 1,000 live } \\
\text { births by 2015 }\end{array}$ & 35 & 69 & $\begin{array}{l}\mathbf{3 4} \text { deaths per 100,000 } \\
\text { live births }\end{array}$ \\
\hline $\begin{array}{l}\text { Reduce the child mortality rate to } 45 \text { per 1,000 live } \\
\text { births by 2015 }\end{array}$ & 35 & 64 & $\begin{array}{l}\mathbf{1 9} \text { deaths per 100,000 } \\
\text { live births }\end{array}$ \\
\hline $\begin{array}{l}\text { Reduce maternal mortality ratio to } 75 \text { per 100,000 } \\
\text { live births by 2015 }\end{array}$ & 75 & 576 & $\begin{array}{l}\mathbf{5 0 1} \text { deaths per 100,000 } \\
\text { live births }\end{array}$ \\
\hline $\begin{array}{l}\text { Achieve 25 percent reduction in HIV adult } \\
\text { prevalence every five years }\end{array}$ & $2.67 \%$ & $3 \%$ & 0.33 percentage points \\
\hline
\end{tabular}

Source: extracts from Joint Assessment Team Report

Amongst the barriers to the successful implementation of the policy, as enumerated by the joint assessment team were: 


\section{International Journal of Social Science and Economic Research}

ISSN: $2455-8834$

Volume:05, Issue:12 "December 2020"

- Weak capacity among implementers in the areas of service delivery, advocacy and social mobilisation, and monitoring and evaluation across all sectors

- Lack of resources for the implementation of activities, characterised by delayed or nonexistent release of funds

- Limited content knowledge - including roles and responsibilities - among intended implementers, due to 1) poor institutional memory of the policy formulation era and proceedings and 2) inadequate dissemination of the policy itself; this has led to actual and perceived non-implementation

- Declining policy content relevance in light of new and emerging population and development issues such as conflict- or insecurity-induced migration and displacement

- Limited relevance to subnational levels due to national focus of policy targets

- Limited political will for population activities among policymakers, influencers, and community/religious/traditional leaders overall, linked to insufficient dissemination and sensitisation activities

The joint implementation assessment team recommended amongst others, improved public sector funding for health, capacity building for delivery of health services and the development of the health sector in general. This is more so because the implementation strategies for healthrelated thematic area include reproductive and sexual health, family planning and fertility management, women's health and safe motherhood, child health and survival, HIV/AIDS, and male reproductive health(Federal Republic of Nigeria, 2004). The target being to manipulate the proximate determinants of fertility.

\section{Loop holes in the 2004 revised population policy}

Reasons proffered for the perceived failed implementation of the 2004 revised population policy on the part of the health sector included inadequate government funding particularly at subnational levels (e.g., delayed release of funds); dependence on donors for programming, and poor coordination of donor activities leading to inefficient redundancies (data gathering, M\&E, etc.); insufficient human resources for health, particularly well-trained personnel; insufficient commodities and supplies, particularly for family planning and maternal health; poor and delayed health management and information systems.

Consequently, we examine the preparedness of health sector in Nigeria to deliver interventions for the attainment of the National population policy targets. 
International Journal of Social Science and Economic Research

ISSN: 2455-8834

Volume:05, Issue:12 "December 2020"

\section{Discussion}

\section{Current profile of the health sector in Nigeria}

\section{Health care delivery in Nigeria}

Nigeria is greatly underserved in regards of her health care needs. Health care resources including infrastructure and personnel are grossly inadequate, especially in rural areas. The healthcare system is dominated by the public sector in comparison to health care delivery by the private sector, but this dominance has not been maximized for effective health care delivery. Health care is delivered at the primary, secondary and tertiary levels, with the primary health care serving the rural populations, while the secondary and tertiary level health facilities are distributed in the urban areas. A flaw of the health system is that is it shrouded with inefficiencies and inequities. This is evident in health care resource allocation which is skewed in favor of secondary and tertiary care as against primary care and Primary HealthCare (PHC) centres (Abimbola et al, 2015; and Oyedeji, 2014).A direct consequence is the heavy reliance on secondary and tertiary care, as individuals in need of healthcare bypass PHC facilities to seek primary care at secondary and tertiary facilities. According to Okpani and Abimbola (2015), this situation is both inefficient and promotes inequities. This is because the cost of primary care provision at secondary and tertiary level is higher (economically inefficient) and poor people, especially in rural areas, cannot access care because it is either not available or too expensive for them (inequity in access and payment). The distribution of the health workforce is also skewed in favor of secondary and tertiary facilities located in urban areas. This more so as incentives for health workers to accept rural postings are often non-existent or poorly applied and the government has done little or nothing to control the geographic location of health facilities by both private and public sector owners leading to allocative inefficiency - overprovision in some areas while other areas are not covered. This inefficiencies and inequities impact on the successful implementations of policies and programmmes of which the population policy is no exception.

According to the 2009 communique of the Nigerian national health conference, health care system remains weak as evidenced by lack of coordination, fragmentation of services, dearth of resources, including drug and supplies, inadequate and decaying infrastructure, inequity in resource distribution, and access to care and very deplorable quality of care. This is coupled with the lack of clarity of roles and responsibilities among the different levels of government to have compounded the situation (Nigeria National Health Conference, 2009).

Primary health care in Nigeria 


\section{International Journal of Social Science and Economic Research}

ISSN: $2455-8834$

Volume:05, Issue:12 "December 2020"

Although primary care is supposed to be the bed rock of universal health care delivery in Nigeria, it is yet to be fully developed for the implementation of policies. This is chiefly due to the lopsided resource allocation, lack of infrastructure and lack of manpower. The LGA which is responsible for primary healthcare is the least funded and organised of the three levels of government. Nigeria's poor health indices and lack of significant progress towards the attaining the targets of the population policy and millennium development goals (MDGs) has been directly attributed to the failure of the primary healthcare system which is currently characterized by extensive dilapidation of healthcare infrastructure, poor financing, lack of modern equipment, lack of supplies, absence of laboratories, inadequate and poorly trained manpower and consequent absence or poor quality of services and loss of confidence in the system (Health Market Report, 2019). To effectively implement the population policy, there is need for the Federal and State Government's to focus on strengthening the primary healthcare system, increasing access to quality services, increasing access to sexual and reproductive health services and contraceptives and decreasing the number of infant, maternal and child deaths from preventable causes.

\section{Human resources for health}

For policies to be fully implemented, skilled and adequate number of manpower is needed. Nigeria has one of the largest stocks of human resources for health (HRH) in Africa but, in comparison to its population, is listed as one of the 57 human resources for health (HRH) crisis countries. This is because the densities of nurses, midwives and doctors are too low (1.95 per 1,000)to effectively deliver essential health services (WHO, 2019).In many rural areas, primary health care facilities are managed by just one individual who is saddled with the responsibility of care for all the residents in the facility's catchment area. This situation, has been worsened by the brain -drained caused by the migration to health personnel to other countries in search for greener pastures, and the reluctance of health personnel to work in rural areas. This reluctance is fostered by high-levels of underdevelopment in these areas, and the lack of incentives from the government to work in these areas. This has contributed to abysmal delivery of sexual and reproductive health services including family planning, youth-friendly counseling services, fertility management, women's health and safe motherhood, child health and survival, HIV/AIDS, male reproductive health and other health interventions needed to control fertility and population growth. It is hoped that with the current task-shifting and task-sharing policy, more adequately trained man power will be recruited to deliver health care services at the primary level of care.

\section{Maternal and child health}


International Journal of Social Science and Economic Research

ISSN: 2455-8834

Volume:05, Issue:12 "December 2020"

Maternal and neonatal health status in Nigeria is abysmal with maternal deaths accounting for $19 \%$ of the global maternal deaths. The maternal mortality ratio is 576 per 100,000 live births (NDHS, 2013). Lifetime risk of maternal death in Nigeria is 1 in 23 compared to 1 in 36 in subSaharan Africa. This situation is worsened by the high rural population in Nigeria $(50 \%)$, and the poor performance of primary healthcare. In addition, the utilisation of maternal health services is low especially in rural areas, with the proportion of women who gave birth between 2008 and 2013 and who delivered their last child with the help of a health professional(doctor, nurse, or auxiliary midwife), according to the 2013 NDHS, was only 38.1 percent, while the proportion of mothers that delivered in a health facility was 36 percent. According to the 2015 estimates produced by the World Health Organisation, UNICEF, UNFPA and the World Bank, maternal deaths in Nigeria were estimated at 58,000;this constituted 19 percent of the global estimate of 303,000 maternal deaths. The high levels of maternal deaths in Nigeria, defy the targets of the population policy.

One quarter of all under-five deaths in Nigeria are newborns- 241,000 babies each year. Nigeria's neonatal death rate (death of infants in the first 28 days of life), as indicated by the NDHS, was 37 per1,000 live births for the 2008-2013 period. The leading causes of neonatal death are intrapartum related, or 'birth asphyxia' (28\%), complications of preterm birth (30\%), and severe infections (22\%), which are preventable health condition. The Federal Ministry of Health, reports that "more than half of neonatal deaths occur during the first week, reflecting the intimate link of new born survival to the quality of maternal care" (FMOH, 2017. Factors associated with the poor state of neonatal health and survival in Nigeria include poor health seeking behavior on the part of parents, inadequate access to maternal and neonatal health services, and poor quality of services.

For population policies to be effective, there is need to strengthen primary health care delivery in the rural areas. Of recent, the Federal Ministry of Health and development partners have intensified efforts at attaining Universal Health Coverage (UHC) for evidence-based and costeffective $\mathrm{MNCH}$ interventions such as focused antenatal care, skilled birth attendance at delivery, free distribution of contraceptive commodities, insecticide-treated nets and provision of comprehensive and basic Emergency Obstetrics and Newborn Care (EmONC).

\section{Contraceptive use and family planning in Nigeria}

Use of modern contraceptive and the uptake of family planning have been identified as having direct implications on reduction of fertility rate and population growth (Shofoyeke,2014). However the effective use of these services, has been hampered by inadequate or absence of commodities and supplies, lack of awareness on the availability and use of these services, lack of man power to deliver these services and traditional beliefs amongst others. The modern 


\section{International Journal of Social Science and Economic Research}

ISSN: $2455-8834$

Volume:05, Issue:12 "December 2020"

contraceptive (mCPR) uptake in Nigeria is low and has been recognized as a key factor in Nigeria's levels and trends in fertility. According to the targets of the 2014 NPP, the modern contraceptive prevalence rate (mCPR) among married women should have reached at least 30.2 percent by 2015 (see Table 3), but statistic reveal that mCPR increased to just 9.8 percent, representing a 1.6 percentage point increase over the 11-year NPP period(NPopC, 2014). There has been commitment by government Nigerian government committed to providing contraceptive commodities at no cost to states since 2011, and a restructuring of the health system through the national Family Planning Blueprint and the Task-Shifting and Task-Sharing Policy for Essential Health Care Services. It is believed that this restructuring will increase the uptake of modern contraceptive and family planning services for effective fertility control.

\section{Conclusion}

We evaluated population policies and the reasons for their inability to check population growth and fertility rates within the period under review (1988-2015). We examined the health-related targets of the policies and the capacity of the health sector to deliver on these targets. We conclude that a functional and effective primary health care system for implementing population control strategies and attainment of health-related population targets. In addition, population policies and health policies have to be synergized as there exists a feedback effect between them. Population dynamics have implications on health planning and health care delivery, while an effective health care system is sacrosanct for the successful implementation of population policies.

\section{References}

Adegbola, O. (2008). Population Policy Implememtation in Nigeria, 1988-2003. Population review. 47(1). doi:10.1353/prv.0.0000

Alaba O.O., Olubusoye O. E.\&Olaomi J. O. (2017). Spatialpatterns and determinants of fertility levels among women of childbearing age in Nigeria, SouthAfrican Family Practice, 59:4, 143-147, DOI: 10.1080/20786190.2017.1292693

Ankomah A; Anyanti, J; Adebayo,S; \&Giwa, A. (2013). Barriers to Contraceptive Use among Married Young Adults in Nigeria: A Qualitative Study. International Journal of TROPICAL DISEASE \& Health 3(3): 267-282. retrieved from www.sciencedomain.org

Avong, H.N.(2000); Perception of, and Attitudes toward the Nigerian Federal Population Policy, Family planning program and family planning in Kaduna state, Nigeria:African Journal of Reproductive Health 4(1) pp66-76. 


\section{International Journal of Social Science and Economic Research}

ISSN: $2455-8834$

Volume:05, Issue:12 "December 2020"

Casterline, J.(2001); The pace of Fertility Transition: National patterns in the second half of the twentieth century: Population Development Review 27pp17-52

CMH (2001). Macroeconomics and health:investing in health for economic development.Commission on Macroeconomics and Health. Geneva: World Health Organization.

Federal Republic of Nigeria. (1988). National Policyon Population for Development, Unity, Progressand Self-reliance, Lagos: Federal Ministry ofHealth.

Federal Republic of Nigeria. (2004). National Policyon Population for Sustainable Development,Lagos: Federal Ministry of Health.

LuciA.,\&Thevenon O. (2010). Does economic development drive the fertility rebound in OECDcountries?. 2010. ffhal-00520948ff

Makinwa-Adebusoye, PK, Feyisetan BJ. (2001). The quantum and tempo offertility in Nigeria. In: Macro International Inc. Fertility trends anddeterminants in six African Countries, DHS regional analysis foranglophone Africa. Calverton, Maryland: MacroInternational;p. 41-86

Mazrui, A.A. (1994); Islamic Doctrine and Politics of Induced Fertility Change:An African perspective, Population and Development Review 20.pp121-134

Mundi R., Dakyes S. P. (2016). Nigeria's population policy: anassessment of the factorsmilitating against fertilitydecline. Case study of federlcapital territory, Abuja. Abuja Journal of Geography and Development Vol. 4 No. 1

National Population Commission and ORC Macro (2004). Nigeria Demographic and Health Survey 2003. Calverton, Maryland, USA: National Population Commission and ORCMacro.

National Population Commission (2009). "Population Figures and Growth Rate Based on 2006 Populationand Housing Census." Federal Republic of Nigeria Gazette 96:Feb. 2009.

Nigeria National Health Conference (2009) Communique. Abuja, Nigeria. [Last accessed on 2010 Nov 5]. Available from: http://www.ngnhc.org .

NDHS (2013). Nigeria Demographic and Health Survey (NDHS). National Population Commission (NPC), Federal Republic of Nigeria and ICF International. Abuja, Nigeria: NPC; and Rockville, MD: ICF International.

NDHS (2018). Nigeria Demographic and Health Survey (NDHS). National Population Commission (NPC), Federal Republic of Nigeria and ICF International. Abuja, Nigeria: NPC; and Rockville, MD: ICF International. 
International Journal of Social Science and Economic Research

ISSN: 2455-8834

Volume:05, Issue:12 "December 2020"

NPC (2015). Nigeria’s 2004 National Policy on Population For Sustainable Developmentimplementation assessment report. National Population Commission.

Obono 0. (2003). Cultural Diversity and Population Policy in Nigeria. Population and development review. 29 (11); 103-111

Odeh, O. (2014). Family planning: Nigeria, others decry cultural barriers. Daily Independent, Monday, February 03. Retrieved from http://dailyindependentnig.com/2013/11/familyplanning

Renne, E.P.,(1996). Perceptions of Population Policy, Development and Family Planning Programmes in Northern Nigeria, Studies in Family Planning 27(3) pp127-136

Shofoyeke A.D.(2014).An Appraisal of the 2004 National Policy on Population for Sustainable Development. Mediterranean Journal of Social Sciences. Vol 5 No 23

UNFPA (2012). The United Nations Population Fund. Population matters for Sustainable Development

UN (1994). Report of the International Conference onPopulation and Development, Cairo, 5-13 September 1994, A/CONF.171/13, 18 October1994, New York, NY.

UN (1992). Report of the United Nations Conferenceon Environment and Development, Rio de Janeiro, 3-14 June 1992, Annex I: Rio Declaration on Environment and Development,A/CONF.151/26 (Vol. I), 12 August 1992, NewYork, NY.

United Nations (2014). World fertility report 2013: Fertility at the extremes.Department of Economic and Social Affairs, Population Division.

United Nations (2017). World Population Prospects: The 2017 Revision, KeyFindings and Advance Tables: Department of Economic and Social Affairs,Population Division; 2017. Working Paper No. ESA/P/WP/248

World Bank (2019). Nigeria Overview https://www.worldbank.org/en/country/nigeria/overview World Bank. (2010). Determinants and consequences of high fertility: a synopsis ofthe evidence. 2010. http://www.worldbank.org/ hnp publications.

WHO (2019)https://www.who.int/workforcealliance/countries/nga/en/ 